\title{
FENOMENOLOGIA EM MICHEL HENRY: IMPLICAÇÕES NA PSICOPATOLOGIA E PSICOTERAPIA ${ }^{1}$
}

\author{
Phenomenology in Michel Henry: Implications in Psychopathology and Psychotherapy
}

Fenomenología en Michel Henry: Implicaciones en Psicopatología y Psicoterapía

Andrés Eduardo Aguirre Antúnez

Karin HeLlen KePLer WONDRACEK

\begin{abstract}
Resumo: A fenomenologia em Michel Henry caracteriza-se pelo reportar de todos os movimentos da vida subjetiva ao seu solo original: à afetividade. É pela declinação no afeto que a intencionalidade, a consciência, as prestações transcendentais do sujeito são simultaneamente fenômenos vivenciados na dupla dimensão do sofrer / fruir. As implicações da fenomenalidade do afeto nesta dupla dimensão interessam à psicopatologia e psicoterapia. O essencial da nossa atividade prende-se com a possibilidade fenomenológica da passagem do sofrer ao fruir da vida. É neste contexto que a fenomenologia de Henry entra no Brasil (Faculdades EST e USP): atendemos à possibilidade da passagem do poder do sentimento (sofrer o afeto) ao sentimento de poder (fruir do afeto). Como parceiros da nossa investigação temos o grupo «O que pode um corpo?», coordenado por Florinda Martins, que desde os anos 80 trabalha a fenomenologia da Vida, na articulação direta com a medicina e com o papel do corpo na redefinição da fenomenologia. O pathos primordial é o afeto na Vida que se torna paradigma de relação terapêutica. Assim, a melancolia ou os traumas psíquicos são ressignificados antropológica e clinicamente, abrindo novas possibilidades terapêuticas na relação entre fenomenologia e psicoterapias, na dimensão do originário e do irrepresentável.
\end{abstract}

Palavras-chave: Fenomenologia da vida; Ipseidade; Sofrimento; Psicopatologia; Psicoterapia.

Abstract: Phenomenology in Michel Henry is characterized by the reporting of all movements of the subjective life to their original ground of primordial affect. It is by the declension of affect that intentionality, conscience, and all transcendental reports of the subject are simultaneously phenomena lived in the two-fold dimension of suffering/joy. The implications of this phenomenology are of special interest to the health sciences, namely psychopathology and psychotherapy. The essence of our activity arrests itself with the phenomenological possibility of the passage from suffering to joy of life. It is in this context that Henrys phenomenology enters into Brazil (EST/USP): we attend to the passage of the power of feeling (to suffer affect) to the feeling of power (to enjoy affect). With us as investigative partners is the group "What can a body do?" coordinated by Florinda Martins of CEFi, which since the 1980s has worked with the phenomenology of life, in direct articulation with medicine and the body's role in redefining phenomenology. The primordial pathos is the affect in life that becomes a paradigm of the therapeutic relationship. In the phenomenology of life, melancholy or psychic traumas are clinically and anthropologically resignified, opening new therapeutic possibilities in the relationship between phenomenology and psychotherapies, especially in the dimensions of the originary and irrepresentable.

Keywords: Phenomenology of life; Ipseity; Suffering; Psychopathology; Psychotherapy.

Resumen: La fenomenología en Michel Henry se caracteriza por reportar todos los movimientos de la vida subjetiva a su origen: la afectividad. Es por la declinación en el afecto que la intencionalidad, la conciencia, las prestaciones transcendentales del sujeto son fenómenos vivenciados en la dupla dimensión del sufrir / fruir. Las implicaciones de la fenomenalidad del afecto en esta dupla dimensión interesan a la psicopatología y psicoterapia. Esencial es la posibilidad fenomenológica del pasaje del sufrir al fruir de la vida. Es en este contexto que la fenomenología de Henry entra en Brasil (Facultades EST y USP): en el pasaje del poder del sentimiento (sufrir el afecto) al sentimiento del poder (fruir del afecto). Como compañeros de investigación el grupo «Lo que puede un cuerpo?», coordenado por Florinda Martins, que desde 1980 trabaja la fenomenología de la Vida, en articulación con la medicina y con el cuerpo en la redefinición de la fenomenología. El pathos primordial es el afecto en la Vida que se torna paradigma de la relación terapéutica. Así, la melancolía o los traumas psíquicos son re significados antropológica y clínicamente, abriendo nuevas posibilidades terapéuticas en la relación entre fenomenología y psicoterapias, la dimensión del originario y irrepresentable.

Palabras-clave: Fenomenología de la vida; Ipseidad; Sufrimiento; Psicopatologia; Psicoterapia.

\footnotetext{
1 Os autores agradecem à Professora Florinda Martins, coordenadora científica do grupo “O que pode um corpo?”, do Centro de Estudos em Filosofia - CEFi - da Universidade Católica Portuguesa, por suas contribuições na discussão desse texto.
} 


\section{Introdução}

Michel Henry nasceu a 10 de janeiro de 1922 em Haïphong, Indochina, atual Vietnã. Segundo filho de um comandante naval e de uma pianista, ficou órfão de pai aos dez dias de vida, morto num acidente de carro. Sua mãe renunciou à sua carreira para se dedicar à educação dos dois filhos. Da infância, Henry mantém na memória os jogos em um grande jardim e as longas viagens no mar quando voltavam das férias de verão na França. Da vida no Oriente, traz o amor pelas antigas civilizações da Ásia, o estilo de seus monumentos e suas estátuas (Wondracek, 2010a).

A família mudou-se para a França em 1929. Após um período de aclimatação em Anjou e Lille, residência do avô materno, que era maestro e diretor do conservatório de música, a viúva Henry e seus dois filhos se instalam em Paris. Michel Henry estuda no Liceu Henri IV, e suas qualidades intelectuais chamam a atenção do professor de literatura francesa, Jean Guéhenno. Mas, nos anos finais, a filosofia ganha sua paixão e a escolha para a graduação. Nas aulas preparatórias para a universidade, marca-o o curso com o filósofo Jean Hyppolite, que se torna seu coorientador na graduação, ao lado de Jean Wahl. Estuda filosofia com Paul Ricoeur (que mais tarde esteve na sua banca de doutoramento), Ferdinand Alquié e Henri Gouhier. Durante o inverno de 1942-1943, escreve sua monografia de conclusão sobre Espinosa, intitulada Le bonheur de Spinoza [A felicidade de Espinosa]. O diretor Jean Grenier quer publicá-la pela Editora Gallimard, mas as restrições de papel e a censura nazista impossibilitam-no por longos anos (Wondracek, 2010a).

Em 1943, segue seu irmão à Inglaterra e ingressa na Resistência, numa divisão constituída por intelectuais. Seu codinome foi Kant, pois sempre carregava consigo o Crítica da Razão Pura. Atuou na região de Lyon, controlada por Klaus Barbie, de sinistra memória. A vida na clandestinidade e a necessidade de ocultar-se marcarão profundamente seu pensamento filosófico (Wondracek, 2010a).

Entre 1944 e 1946, procede à revisão de Metafísica e Moral. A guerra impede a possibilidade de aspirar a seguir carreira na filosofia e, em 1945, Michel Henry passa a considerá-la apenas para reflexão pessoal, enquanto ganha a vida ministrando aulas. Lê Sein und Zeit de Heidegger, ainda não traduzido ao francês, e pouco depois visita o filósofo alemão em sua reclusão no chalé de Todtnauberg, durante estadia na Floresta Negra com amigos (Wondracek, 2010a).

Apesar da longa entrevista, que o fascina, já expressa certo descontentamento com a ênfase fenomenológica na exterioridade, primícias de suas críticas posteriores ao rumo tomado pelo pensamento ocidental. (Wondracek, 2010a).

Casou-se com Anne Henry em 1958. Até 1960, as atribuições da Fundação Thiers impedem-no de se dedicar com mais afinco a suas próprias pesquisas. A partir de 1960, torna-se professor titular da Cadeira de Filosofia da Universidade de Paul Valéry em Montpellier, preferida à Sorbonne por ser distante da agitação cosmopolita com seus modismos filosóficos e de ideologias dominantes. Isso lhe dá condições de aprofundar suas próprias reflexões e escrever textos significativos que as explanem. Mantém-se nesse posto até sua aposentadoria, em 1982, apesar dos convites quase anuais de mudar-se para a Sorbonne. Lá, torna-se professor convidado, bem como da École Normale Supérieure de Paris, da Universidade Católica de Louvain, da Universidade de Washington (Seattle) e da Universidade de Tóquio.

A relação de Henry com sua história pessoal é resumida de forma emblemática na entrevista concedida a Roland Vaschalde, que também nos dá uma ideia do seu modo de pensar:

A história de um homem, as circunstâncias que o envolvem, é outra coisa que uma espécie de máscara, mais ou menos lisonjeira, que ele mesmo e os outros estão de acordo em colocar sobre o seu rosto - ele que, no fundo, não tem rosto algum. Você observa que eu nasci em um país distante. É o que me disseram. Mas este país não é mais longe do que a Índia e a China? Para mim, eu nasci na vida, da qual ninguém ainda encontrou a fonte em algum continente. Eu não conheci meu pai - mas não está nisso a condição de todos os seres vivos? O homem do qual minha mãe falou mais tarde era capitão de longo curso, eu o vejo como um personagem de Conrad ou de Claudel. Na verdade, eu nada sabia dele. Mas eu sabia algo a mais sobre a criança que passou seus primeiros anos ali? Nós vivemos em um eterno presente que nunca nos abandona. O que permanece fora dele está separado de nós por um abismo. E isso porque o tempo é um meio de irrealidade absoluta. Eu partilho da opinião do Mestre Eckhart: "O que se passou ontem está tão longe de mim quanto o que se passou há dez mil anos" (Henry, 2007).

Michel Henry morre de câncer, em Albi, França, a 3 de julho de 2002. Em 2006, sua esposa doa à Universidade Católica de Louvain seus arquivos filosóficos e literários. O Fonds d'archives Michel Henry, dirigido pelo Prof. Dr. Jean Leclercq, constitui-se em núcleo de investigação, publicação e divulgação de sua obra.

\section{A Posição de Henry frente à Fenomenologia: $A$ Encarnação e o Outro}

A Fenomenologia da Vida inaugurada por Michel Henry não nega a intencionalidade, mas não a coloca em um lugar principal, visto a consciência ser sempre consciência de alguma coisa, pois se dirige a fenômenos 
exteriores, objetivos e visíveis. Henry volta-se à vida que em si mesma é invisível, dando-se tal como outros fenômenos, por exemplo a alegria e o sofrimento, na esfera da imanência subjetiva, ou seja, experimentam-se na relação imediata de si consigo, em regiões arcaicas e originárias. O que aqui está em causa são duas coisas: crítica da intencionalidade vista do exterior e da intencionalidade em si mesma.

Ao declinar a intencionalidade na afecção de si mesma, Henry desloca a fenomenalidade para uma transcendental, mas concreta imanência, que se interroga pelo ser do ego e pelo seu destino antes de se interrogar pelo ser dos objetos a que o ego se destina (Martins, 2010). É deste modo que a crítica de Michel Henry se posiciona de modo distinto das filosofias da existência e postula a necessidade de recuperar a encarnação do ego. Na vida, a relação eu/tu apresenta-se como afeição primordial e jamais se dá na fragilização do eu pelo outro (Lévinas), mas pelo acolhimento da afecção, ato de afeto ou autoafecção. Com Michel Henry, ganha assim voz a passividade do afeto, o possível da relação (Ricoeur). De modo que a linguagem fenomenológica se renova: o ego fala de si ao falar da Vida em si, da vivência da relação. Nessa relação fazem sentido a estética, a ética, a política, a religião e o pretenso vazio do tempo (Martins, 2002a).

\section{Psicoterapia e Psicanálise: Diálogos Possíveis com a Fenomenologia da Vida}

Em Genealogia da Psicanálise encontramos a melhor explanação henryana dos rumos do pensamento ocidental até a psicanálise; por isso o nome de "Genealogia". Para Florinda Martins, esse livro tem um lugar preeminente nas investigações de Henry porque "as questões do inconsciente são contemporâneas às questões da consciência" (Martins, 2009, p. 36): e remontam a Descartes. A tese central do livro é que o esquecimento da vida como autoafetiva e autoimpressiva conduz a filosofia moderna e contemporânea a relegar a vinda da vida como afeto e a privilegiar o aparecer na exterioridade e tomá-lo como fundamento.

E embora Michel Henry inicie sua análise do pensamento ocidental com a afirmação de Husserl, em seus últimos escritos (Husserl 1970, 1936; Faÿ and Le Guyader, 2009), de que a crise da ciência ocidental deriva de uma decisão intelectual tomada por Galileu Galilei no início do século XVII pela qual o mundo sensível recebeu uma crítica radical, que acarretou a transformação da concepção tradicional de mundo, de ciência e de corpo - será Descartes que levará esta orientação ao limite, mas efetivando ao mesmo tempo uma contra-redução que deixa em aberto todo um outro universo de possibilidades. Esse conhecimento, forjado em campos estranhos, passa a ter a pretensão de "fornecer a verdadeira aproximação ao homem, de o procurar no mais íntimo do seu ser, até no prazer, no coração do seu sofrimento ou do seu desânimo - da sua vida ou da sua morte" (Henry, 2001, p. 105).

Nos primeiros escritos de Descartes se produziu uma contra-redução que novamente privilegiou a subjetividade como forma de conhecimento. Surge um novo conceito de realidade, que passa a se referir não apenas ao universo das coisas, mas também ao ser humano: no início de suas Meditaciones, eu penso significava mais que a atividade mental, pois priorizava o sentir a si - sentir que pensa, que vê, que duvida, que sonha. Henry (2009) apresenta um Descartes imanentista desconhecido na contemporaneidade: no Começo cartesiano, pensar não era ter pensamentos: "parece-me que vejo, que ouço, que me aqueço, sendo isso o que em mim propriamente se denomina sentir, e, considerado de modo mais preciso, não é nada mais do que pensar" (Descartes citado por Henry, 2009, p. 57).

Num segundo momento, na passagem da Primeira para a Segunda Meditação, acontece uma mudança: ao procurar estabelecer o método para o conhecimento objetivo, Descartes desfaz a prioridade deste "sentir que pensa", ou "sentir que vê" e passa agora para a percepção efetiva: "Nesse meu primeiro conhecimento, não se encontra nada mais que uma percepção clara e distinta daquilo que conheço [...] Por isso são verdadeiras todas as coisas que concebemos muito clara e distintamente" (Descartes citado Henry, 2009, p. 86). O importante a partir de então é o conteúdo do pensamento, e não mais a sensação subjetiva de pensar. Como consequência, a via aberta em direção ao Começo foi abandonada e não participou do desenvolvimento cultural do Ocidente, pois neste o ser humano passa a ser definido pela razão e pelos dados na exterioridade do aparecer.

As intenções de assegurar o método e de fixar a ciência ganharam o primeiro plano, desviando-o de suas metas anteriores e relegando-as finalmente ao esquecimento. Assim, a ênfase passou do conhecimento imediato do "pensar" ou "ver" [Videor] para o "pensar algo" ou "ver algo" [Videre]. Deslizamento que foi assumido por Kant (eu como "eu me represento"), passou por Husserl (eu como "intencionalidade") e chegou até Heidegger (eu como "ser-no-mundo"). Henry comenta que a busca da subjetividade viva reaparece em Schopenhauer e Nietzsche, mas neles se reduz ao âmbito do anônimo, selvagem, impessoal, e assim transmite esse tom sobre a filosofia e a cultura, abrindo "as vias da força bruta, da violência e do niilismo" (Henry, 2005, p. 23). Essa "perda do fenômeno na fulguração do seu aparecer" deixa indeterminados não apenas o princípio do conhecimento de si (domínio da antropologia), mas também alcança as possibilidades terapêuticas (domínio da clínica) (Wondracek, 2010a).

Para Henry (2009), a psicanálise recusa a abordagem conceitual do inconsciente dos filósofos que a precederam, e assim alberga a vida, a grande ausente do pensamento ocidental. "Inconsciente é o nome da vida" (Henry, 
2005, p. 116). Freud é um epígono, continuador da obra de Descartes, Schopenhauer e Nietzsche (2009, p. 39). Com a psicanálise se resgata o Começo cartesiano:

(...) num mundo no qual a objetividade não cessa de estender seu reino de morte sobre um universo devastado, quando a vida não tem outro refúgio que o inconsciente freudiano (...) a psicanálise é a alma de um mundo sem alma, o espírito de um mundo sem espírito (Henry, 2009, p. 27).

Freud é herdeiro do conceito cartesiano mais amplo de consciência que tinha sua matriz no sentir-se e não no pensar. Nessa intuição mais profunda de Freud está, para Henry, a noção de que inconsciente é mais do que nãoconsciente, mais do que aquilo que é passível de trazer à luz pela representação, bem como do que é derivado do modelo mecanicista do século XIX (Wondracek, 2010a).

Henry (2009, p. 335) aponta que na esteira de Descartes e Schopenhauer, Freud também faz um "giro capital e catastrófico" e compreende o originário com as categorias do produto, ou seja, pela representação. Por conseguinte, "longe de se opor à clássica filosofia da consciência, como o crê a psicanálise, ela muito mais se desenha como sua estrita continuadora e sua última modalidade" (Henry, 2005, p. 111). A crítica fundamental de Henry é de que a psicanálise recebe na sua genealogia cartesiana o paradigma do monismo ontológico, e assim passa a privilegiar a verdade dada na distância da representação. Assim afasta-se da vida que albergou e, por conseguinte, da possibilidade de perscrutar a vinda da vida como afeto, na imanência (Henry, 2009, p. 339). Gera-se uma situação contraditória, na qual "a crença na ciência e o que é preciso denominar o cientificismo de Freud estão em contradição com sua intuição mais profunda" (Henry, 2009, p. 323). A herança cartesiana nas terapias se mostra no progressivo privilégio que a metapsicologia dá à representação dificultando a abordagem da dimensão afetiva. Conforme o psicanalista Carlos Plastino, "é na inadequação do instrumental teórico utilizado para pensar os afetos e sentimentos que reside a incapacidade de Freud para conciliar sua teoria com a experiência clínica” (Plastino, 2001, p. 62), no que é corroborado por Green (1998), Birman (2007), Schneider (1993), entre outros.

A psicanálise e a fenomenologia têm estabelecido poucos pontos de contato no decorrer da história. Henry aponta que desde Husserl perpassa a impressão de que ambas não partilham do mesmo campo: a psicanálise tem visto a fenomenologia mais no âmbito da consciência e por isso não compartilha dos processos inerentes à teoria de Freud. A fenomenologia clássica, por seu lado, tem olhado com reservas a psicanálise, pois ela não compartilha da importância da intencionalidade (Wondracek, 2010a, p. 17).

A psicoterapia em sua definição etimológica se refere à terapia do psíquico. Com Michel Henry estamos dian- te da afetividade como auto-afecção de si, portanto é na Vida que encontramos a essência do ser humano, na terapia se apresenta a vida absoluta da Vida e do amor, não há resistências ou bloqueios, mas um vivido em primazia quanto às teorias explicativas.

Vivemos em um mundo banhado pela exposição da violência, que nasce no interior de cada um, que não está fora de si mesmo. Assim, para Rolf Kühn² (2010, pp.73-74):

(...) em vez de responder (...) à agressão pela violência real ou simbólica da minha parte, o olhar terapêutico ou clínico apercebe ainda no próprio Fundo desta agressão uma manifestação da Vida absoluta para lhe responder com o sentimento ou o afecto que esta Vida conhece eideticamente a respeito da sua essência própria, a saber, a auto-revelação do seu amor. É assim que se poderia retornar a oposição entre 'resistência' e a transferência afectiva' no sentido freudiano a fim de permitir uma nova abordagem da realidade terapêutica a partir do próprio vivido fenomenológico, e não só a partir de uma teoria ‘metapsicológica' prévia.

Essa nova abordagem do ser humano acolhe, do ponto de vista terapêutico, a Vida que é em sofrimento. $\mathrm{O}$ sofrimento não sendo atacado como um sintoma, mas compreendido em sua ipseidade. "Um sofrimento não se cura mediante a aplicação a priori formal, segundo procedimento habitual nos outros domínios públicos, a saber, por exemplo na política, na economia e nas ciências" (Kühn, 2010, p. 75).

O sofrimento é a própria terapia da Vida e a clínica um lugar para se acompanhar, na intropatia, uma vivência em seu modo de ser e de poder transformar o sofrimento em fruir, em movimento. Vemos uma aproximação com as afirmações de Winnicott (1975), de que o processo criativo transforma experiências e ajuda a atravessar as dificuldades. Nessa perspectiva, a criatividade jamais se perde, em não sendo usada está lá, a espera do gesto do outro, para que seu gesto se realize e a pessoa possa se sentir real, realizada, dando novo sentido e esperança a sua existência.

Henry cria o conceito de modalização dos afetos, para justamente mostrar que a impossibilidade de fuga convida à aceitação do sofrimento e a partir disso à sua modalização, sua transformação em outra disposição afetiva. $\mathrm{O}$ trabalho terapêutico convida à integração do afeto para o encontro com a Vida, doadora de todo afeto, de todo ego. "O incremento da angústia na vida expressa o movimento pelo qual este si - não estático, mas pático - se torna consciente de sua própria natureza” (Henry, 2005). Assim, a dor é da ordem da revelação, da conscientização do Si a respeito de sua própria natureza, e sai do regis-

\footnotetext{
Rolf Kühn é nosso interlocutor e coordenador do Grupo de Investigação em fenomenologia francesa contemporânea na Albert Ludwig Universität em Freiburg, Alemanha [Forschungsstelle für jüngere Französische Religionsphilosophie].
} 
tro expresso de afeto a evitar, e se torna afeto a integrar para depois modalizar.

\section{Outra Compreensão para a Psico-pato-logia}

As ideias de Henry são fecundas para a compreensão do padecimento humano. Segundo Cardoso (2010), sua crítica à Ciência Moderna denuncia a excessiva tendência a objetivar a vida ou a consideração do vivo em abstração, cuja essência é genérica e vazia. Para Henry, a ipseidade é o logos da vida. A vida só pode ser apreendida pela vivência subjetiva. A camada mais arcaica do si é um pathos, um padecer que é a experiência da vida que flui em mim.

Segundo Kühn (2010), podemos refletir sobre a clínica e a relação terapêutica, onde estas ocupam um lugar de refúgio da qualidade da experiência afetiva de si, pois revalorizam a dimensão do encontro e a especificidade da relação terapêutica. Assim, há um co-pathos, onde a compaixão é a capacidade de se auto-afetar pelo pathos do outro. Nesse sentido, a melancolia ou os traumas psíquicos não constituem uma paragem de uma subjetividade afetiva, pois esta é prometida à felicidade de viver.

Na auto-afecção radical enquanto nossa Facticidade individual sempre efectiva, a vida recebe-se em si própria como uma vida que permanece absolutamente idêntica a si própria, e em tal recepção passível dela própria continua a dar-se como a Felicidade enquanto tal. Daí que se possa dizer que a vida, que é a nossa, fica marcada, na sua essência mais interior, pelo suportar-se e pelo gozar-se do seu auto-aparecer (Kühn, 2010, p. 82).

Para dar conta de tal afirmação, é preciso aproximarse à questão fundamental da existência humana que pode ser formulada pela expressão "quem somos nós?” De acordo com Kühn (2010, p. 29), "nós somos consubstancialmente o mero Revelar-Se desta vida que nenhuma linguagem chegará alguma vez a exprimir, e ainda menos o sistema tópico e simbólico do Inconsciente enquanto 'isso' anônimo que vai de Freud a Lacan”, ou como afirma Henry (1976, p. 413), "este saber da vida, que é a própria subjetividade, a sua inquietação, o seu sofrimento ou o seu apetite".

Vivemos em um mundo onde a tecnologia atinge as relações humanas, seja nas ciências exatas, biológicas e também nas ciências humanas, de um modo positivo, mas também de modo negativo. Milhares de seres humanos já não se reconhecem, vivem dispersos em si e não encontram sentido para suas existências. Essas pessoas procuram ajuda, auxílio e socorro. Diante do próprio sofrimento, se dirigem aos hospitais, às clínicas psicológicas e psiquiátricas, aos consultórios particulares, às religiões, em busca de alguém. O sofrimento é de tal or- dem que precisa ser exterminado ou em termos médicos, curados, quiçá a-mortecido. Nas palavras de Martins e Teixeira (2007, p. 27) “ansiedade, húmus de ninguém, a espera de alguém!” Enquanto um alguém não vem, aparece ninguém!

Na concepção de Michel Henry, o sofrimento é parte da Vida e traz consigo a felicidade de viver (Wondracek, 2008). A psicopatologia contemporânea é movida pelo domínio da psiquiatria baseada em evidências, ou seja, fundamentada em observações concretas, objetivas, "visíveis" e verificáveis nos comportamentos. "Quanta cegueira na lucidez das nossas evidências, certezas, representações!" (Martins \& Teixeira, 2007, p. 15).

Kühn (2010) se dirige ao sofrimento e à plenitude. Selecionamos algumas passagens que nos parecem importantes para nossa reflexão: "o mencionado pathos $d a$ Vida é ao mesmo tempo um gozo e um sofrimento primordiais" (p. 64); em relação ao excesso de tecnologia que afeta o ser humano, afirma Kühn (2010, p. 68):

A ideologia dominante da 'complexidade' tecnicista quer, portanto, fazer esquecer que existe uma Vida de cada vez individual muito mais rica em matizes e tonalidades sensíveis e espirituais do que toda a complexidade representável. E esta riqueza da vida de cada um escolheu, em parte, a 'clínica' hoje como um lugar onde ainda é possível intercambiar as necessidades afectivas segundo as suas modalizações interiores próprias. Com efeito, os outros lugares tradicionais de uma reciprocidade ou comunidade vivas, tais como a religião, a arte e a ética encontram-se igualmente no presente marginalizados, se não já destruídos.

Triste realidade que vivemos na contemporaneidade. Dizem que a psicanálise está em crise, não estaria o ser humano sempre em crise? Kühn (2010, p. 70) nos mostra de modo preocupante que:

O que resta, assim, no plano da prática quotidiana, não é, em definitivo, um saber técnico dos 'métodos terapêuticos' ou 'educativos', mas uma intropatia que obedece às leis vivas de troca afectiva real e cuja metagenealogia Michel Henry narrou sob a forma fictícia no seu romance 'O filho do rei', que constitui, a este respeito, ao mesmo tempo, um livro fenomenológico. Efectivamente, aquele que 'educa' e que 'cura' não sabe mais da Vida do que aquele que sofre'. A obra de ficção, em Henry, fala das dores da realidade: ele inicia suas publicações filosóficas com um romance, integrando desta forma o brilhantismo registrado pelo professor de literatura com a paixão pela filosofia.

A partir de evento relatado por um amigo oficial da Marinha, Henry (1954) escreveu em 1947 outro romance, Le jeune officier, sobre a tentativa de desinfestar um navio dos ratos. O livro aborda a vanidade desse intento e a 
amplia para a impossibilidade de dar uma estrutura lógica à vida, retratando assim, no dizer de Martins (2002a), o "sentimento de fracasso perante a impossibilidade de erradicar o sofrimento das nossas vidas".

Na base, está o conceito de passibilidade do ego, que recebe e experimenta a vida desta forma, tanto o seu gozo como seu sofrimento. O corpo não é só ação, mas fundamentalmente pathos, paixão, no reconhecimento de uma passibilidade radical, que simultaneamente é revelação:

A impossibilidade do sofrimento de a si mesmo escapar de se referir a si afastando-se de si, no manterconjunto de um ver, de uma sín-tese, por mais passiva que seja - é tão-só o inverso de uma positividade absoluta: essa vinda a si no sofrimento, na sua paixão, nessa identidade consigo que é a sua substância mesma. A paixão do sofrimento não é só o que a interdita, para sempre, evadir-se e fugir de si mesmo: ela só significa essa interdição porque é primeiro essa vinda a si do sofrimento que a carrega com o seu próprio conteúdo e a une indissoluvelmente a ele. A paixão do sofrimento é o seu jorrar a si mesma, o ser apreendida por si, a sua aderência a si, a força em que coincide consigo e na força invencível dessa coerência, dessa identidade absoluta consigo na qual se experiencia e se revela a si mesma, a sua revelação - a sua parusia (Henry, 2001, p. 65).

Essa impossibilidade de fuga remete ao poder doador da vida, e convida a sair da percepção do corpo como objeto para o corpo como lugar de revelação da vida e da identidade. São as ideias do filósofo Maine de Biran (1766-1824) que concedem a Henry um ponto de partida para desenvolver a sua própria intuição na direção de uma filosofia da imanência concreta, uma concepção de sujeito pensado como ser humano real, encarnado, em oposição ao ser humano abstrato do idealismo. Maine de Biran compreende o cogito originário como esforço [effort] volitivo-corporal e não como algo reflexivo, ao modo de Descartes.

Henry dá especial relevância à intuição de Biran do corpo subjetivo, da subjetividade encarnada ou corps vivant [corpo vivente]. A realidade fenomenológica do ego é ser "corpo subjetivo". O ego como corpo subjetivo não é objeto do mundo que é experimentado, mas é imanente, localizado no coração da realidade humana. A imanência do ego anula o dualismo mente e corpo e torna possível a unidade do poder do ego como ação, emoção, intelecto, num único movimento da passibilidade de si, como Eu posso. Esse poder do ego se dá na imediaticidade, ou seja, na não-representação, sem distância entre o que experiencia e o que é experienciado.

Michel Henry sente a vida em seu estado presente, e essa interessante noção traz contribuições para a empatia ou intropatia, muito útil para compreender a clínica psicológica e psicanalítica, que se alimentam de modo profícuo com a filosofia fenomenológica. Nesse sentido a temporalidade humana é vivida em sua complexidade. "Husserl na filosofia da intersubjetividade mostra que a intropatia, nas primeiras relações, gera a pessoa não apenas no tempo presente, mas para além dele, porque a abrem ao futuro" (Martins \& Teixeira, 2007, p. 23). Devir que muitas vezes está esgarçado em nossos pacientes, que nos procuram para inconscientemente aproveitarem a vida, daqui em diante, de outro modo, que ainda não foi possível.

Todo olhar clínico, enquanto olhar transcendental do médico ou terapeuta visa, por detrás dos diagnósticos ou operações, "um ser único no seu sofrimento e na sua esperança, quer dizer, na sua verdade transcendental” (Kühn, 2010, p. 73).

\section{Considerações Finais: Desafios do Afeto e do Cor- po}

A psicoterapia e a psicanálise tentam dar conta dos diversos problemas psicológicos, psiquiátricos e psicopatológicos; o diálogo com a fenomenologia da Vida nos ajuda a refletir a importância na contemporaneidade dessas atividades íntimas que acontecem entre dois. A clínica é um lugar onde é possível revelar o visível, mas principalmente o invisível, a saber: a afetividade, a alegria, o prazer, a depressão, o desespero, a melancolia, os traumas, ou seja, aquilo que é invisível, mas existe! De acordo com Martins e Teixeira (2007, p. 16) “a fenomenologia da vida, de Descartes a Henry, encontrara no corpo dotado de sentidos, impressões, sínteses passivas, afectividade, afectos, essa conaturalidade do sensível com o incondicionado. Não já 'animal racional', mas afectividade: transcendental na sua sensibilidade".

Em outras palavras, a fenomenologia da Vida nos auxilia a sensibilizar-nos ao trabalho clínico com o afeto como fundamental do acontecer humano, pois remete à doação originária da vida em cada um. Em meio à sofisticação teórica atual, o afeto corre o risco de ser obscurecido (Kristeva, 1988; Plastino, 2001). Mais do que compreender a história, dentro da relação causa-efeito, a proposta é buscar sentir e apontar como a pessoa frui ou não à vida - aqui uma escrita falha que deixamos falar por si - avidez, gana, pulsão -, esta força da vida que se mostra ou é posta a calar. Na caminhada com o paciente, desde as entrevistas iniciais, assinalar quando há fruição ou fuga da manifestação da vida, do sentir ou deixar de sentir-se; do sentir-se vivo ou não.

A clínica que se revela como compreensão do outro, na intersubjetividade, mostra que é possível contemplar o outro, em respeito profundo a seu modo de ser e de se expressar em sua ipseidade, de ser semelhante a nós, prestando atenção ao modo peculiar da vida se manifestar nele e por ele. A biografia de nosso paciente é diferente 
da nossa, mas como afirma Safra (2004, p. 147), nós caminhamos juntos nas intempéries da existência, vivemos o mesmo destino: a condição humana, o mit-pathos comum, alicerçados num Fundo comum doador da vida (Kühn, 2010; Wondracek, 2010a).

Quando nos referimos à psicoterapia ou à terapia do psíquico, nessa expressão algo não aparece, o corpo. $\mathrm{Na}$ perspectiva de Michel Henry, temos o corpo e temos a carne, "esta carne viva que somos realmente e que nos incumbe hoje redescobrir, apesar do objetivismo reinante." (Henry, 2001, p. 273) O conceito de carne visa justamente salientar a qualidade da vida como auto-impressiva e afetiva. O corpo pode ser visto de modo desfigurado, mas para o sujeito o seu corpo pode ser "vivo, sensível, afectivo!” (Martins \& Teixeira, 2007, p. 22). Carne é esse corpo transcendental que não é mais do que a corporeidade imanente que encontra a sua essência na vida (Magalhães, 2008, p. 29). A carne invisível é a "autodoação primitiva”, "um tipo de sabedoria própria do estado de inocência original”, a "memória imemorial dos nossos poderes", na qual eles se experimentam interiormente "sem recordar nem antecipar" (Lipsitz, 2004, p. 73).

Um mundo desumano pode então ser banhado pela fenomenologia e esta usada na clínica terapêutica, na psicoterapia e na psicanálise, para que reencontrem o seu vigor original de portadores da vida (Paincera, 2002; Henry, 2009). Expressa Martins em seu prefácio ao Genealogia da Psicanálise de Michel Henry:

E a busca das fundações para a psicanálise, enquanto referida à vida que cada um vivencia, talvez possa trazer uma nova luz às questões dos hard problem da consciência, pois não busca harmonizar os dados da neurologia com os da fenomenologia, mas atende à vida aí onde ela se revela a si mesma, no seu pathos. É na vivência do corpo, do nosso corpo, uma vivência irredutível a toda e qualquer cousificação que fazemos a prova dessa vida que advém a si como nós e que não pode ficar esquecida em qualquer processo científico ou terapêutico (Martins, 2009, p. 31).

Mas não uma terapia do psíquico ou uma análise da psique que coloque as representações mentais ou simbólicas como alvo a ser conquistado em primeiro plano, mas que leve em conta a sensibilidade e a afetividade em um lugar fundamental da constituição e da origem humana. Mas o que é o humano para a fenomenologia de Michel Henry? Ser em devir!

Martins e Teixeira (2007, pp.32-33) escrevem facetas da vida de forma profundamente poética:

A fenomenologia chama apelo do ser a ser-se o próprio! E isto porque o humano não é um facto é um ser em devir. Guimarães Rosa tem uma expressão curiosa para dizer esta realidade: o diabo não precisa de existir para haver; deus existe mesmo quando não há! O facto sem liberdade de ser, o haver, não é o que caracteriza o ser humano. Despertar para um universo de possibilidades, quaisquer que elas sejam, é possibilidade de sermos e de existirmos. À célebre definição de 'animais racionais' a fenomenologia substitui esta: possibilidade de sermos.

Assim, todo acontecimento humano, que inclui o pathos, e o co-pathos na intropatia que se revela na psicoterapia, encontra-se referido ao ethos humano. De acordo com Safra (2004, p. 122) "a partir desse ponto de vista, podemos compreender o sofrimento humano, a psico-pathos-logia, como a notícia da maneira peculiar como uma pessoa conseguiu ou não pôr em marcha as questões de sua existência”. Na terapia aguardamos, contemplamos, acompanhamos e dialogamos, não só o que já foi pensado ou o já acontecido, mas nos abrimos para o que ainda não foi possível, na esperança eterna de despertar um dia para sermos, para existirmos e para o ainda não acontecido.

No Brasil, o diálogo entre fenomenologia da Vida e as psicoterapias está apenas começando (Wondracek, 2010b). Nossa participação no grupo de investigação internacional "O que pode um corpo?" (Martins, 2010) tem como objetivo o seu aprofundamento, e certamente trará frutos para nossos campos.

O projeto 'O que pode um corpo? ${ }^{\text {’' }}$ se insere:

(...) no espaço aberto pela fenomenologia, procura na fenomenologia do corpo, resposta às questões que a cultura nas suas diferentes formas de manifestação hoje nos põe: o corpo encerra uma alteridade que pode ser reconhecida no exercício dos poderes do meu corpo e é irredutível a qualquer uma das minhas determinações sobre ele (Martins, 2010, p. 21).

A passagem da fenomenologia do ser à fenomenologia do ser do ego: Michel Henry (2006, pp.1-2) desenvolve uma fenomenologia não-intencional, como uma tarefa para uma fenomenologia futura, como um projeto crítico da fenomenologia intencional, mas não se limita a ela, e sim "visa a filosofia em geral numa parte importante de seu desenvolvimento" (p. 1). Esta "fenomenologia nãointencional assume para si mesma a tarefa de fundar a própria intencionalidade” (p. 2).

Uma parte importante toca no íntimo de todo trabalho clínico e terapêutico, que busca o verdadeiro de cada pessoa. Nesse sentido, a partir da fenomenologia de Michel Henry encontramos uma citação que se irma-

\footnotetext{
Protocolo de colaboração para o desenvolvimento de uma rede de estudos internacional sobre Michel Henry, firmado entre CEFi Centro de Estudos de Filosofia da Faculdade de Ciências Humanas da Universidade Católica Portuguesa e as Faculdades EST, São Leopoldo, Rio Grande do Sul; Sigmund Freud Associação Psicanalítica de Porto Alegre, e Departamento de Psicologia Clínica do Instituto de Psicologia da Universidade de São Paulo, Brasil, em Lisboa, 10 dezembro de 2010 .
} 
na a esta busca essencial da relação entre um terapeuta e seu paciente:

Se a fenomenologia - esta fenomenologia - toma em consideração não os objectos, mas a maneira como eles se nos dão, é unicamente para chegar ao serverdadeiro dos objectos, para lá da sua aparência ou da sua intencionalidade. É preciso que o ente se dê em si mesmo tal como é, de modo que possamos obter dele um conhecimento verdadeiro. Se a doação que está em questão, na fenomenologia de Husserl e de Fink, implica esta relação essencial com o ente, é porque, enquanto doação, ela é precisamente a visão na qual o ente se descobre originariamente para nós no seu ser verdadeiro (Henry, 2006, p. 7).

Neste artigo, Michel Henry traz para lá da intencionalidade, o mundo misterioso do ser humano, a saber, a sua própria vida e como ela se revela, para que “(...) o auto-aparecer apareça por si mesmo, por e na sua fenomenalidade própria, sem nada pedir ao ver da intencionalidade nem à visibilidade de um mundo" (Henry, p. 12). Na sequência traz um conceito muito caro para o sentimento que surge a cada encontro humano na clínica, que se revela como auto-revelação. Henry afirma:

(...) é somente fora da intencionalidade, independentemente de todo o horizonte extático da visibilidade que se cumpre a Arqui-Revelação constitutiva do auto-aparecer do aparecer. Arqui-Revelação porque, dando-se fora do Ex-stase independente dele, realizase 'antes' dele. Esta Arqui-Revelação enquanto um auto-aparecer é, realmente, o mais misterioso, mas também o mais simples e o mais comum: é aquilo que toda a gente conhece - a vida (Henry, 2006, p. 13).

Henry descreve com acuidade filosófica e humana o que os terapeutas sentem na clínica, no encontro com um paciente, tão difícil de nomear, que de tão simples, buscam explicações - por vezes vestidas de compreensão em teorias, buscando iluminar o simples com o complexo abstrato de teoremas meta-psicológicos. É nesse sentido que buscamos articular sua fenomenologia ao campo psíquico. Henry (2006, p. 13) afirma:

A vida é fenomenológica num sentido original e fundador. Não é fenomenológica no sentido em que também ela se mostraria, [em que seria mais] um fenômeno entre outros. É fenomenológica no sentido em que é criadora da fenomenalidade. A fenomenalidade surge originalmente ao mesmo tempo que a vida, sob a forma de vida e de nenhuma outra maneira. A fenomenalidade acha sua essência original na vida porque experencia-se a si mesma [s'éprouve soi-même], de tal maneira que este experenciar-se é o auto-aparecer do aparecer.
O desenvolvimento dessa fenomenologia não-intencional vai se dirigindo para outro campo fundamental à clínica, aos cuidados terapêuticos, a saber: a afetividade, àqueles sentimentos tão presentes a cada encontro, no qual os pacientes gostariam de se livrar, porém livrando-se deles, perderiam a própria vida. Assim continua Henry:

A fenomenalidade de tal auto-aparecer, a substância fenomenológica de puro experenciar-se é uma afectividade transcendental, a única que torna possível qualquer coisa como o medo, o sofrimento ou a alegria - qualquer coisa, com efeito, que se experencie a si própria e a pensa consigo se relaciona e cuja relação é a sua afectividade (p. 13).

Se para a psicoterapia o campo da afetividade é primordial para qualquer relação de ajuda, já que por vezes é ela que obscurece a melhor das capacidades intelectuais ou cognitivas, dada sua complexidade, para a fenomenologia da vida a afetividade tem um papel fundamental e originário, esclarecendo o que se revela no encontro humano. Nas palavras de Henry (2006, p. 13): “A afectividade é a essência fenomenológica da vida, a carne impressional em que o ver da intencionalidade não tem lugar - nesse sentido, [a afectividade] é o não-intencional puro". Desse modo, a fenomenologia da vida revela que a afetividade aparece em toda relação psicoterapêutica na sua não-intencionalidade pura, antes mesmo de qualquer representação de palavra, sempre secundária à fonte originária do viver. Michel Henry opera em uma redução fenomenológica radical (distinta à redução fenomenológica de Husserl), pois a fenomenologia da vida, "é uma redução fenomenológica radical, no sentido em que não diz respeito a nenhum ente, mas à própria fenomenalidade" (Henry, 2006, p. 14).

É notório que para muitos psicoterapeutas as teorias meta-psicológicas não conseguem dar conta do amplo fenômeno que acontece em uma relação analítica, como bem diz Henry (2006, p. 18):

O universo da representação não se explica nunca por si próprio, tal como o pensamento moderno tentou dizer, de Schopenhauer a Freud. (...) Quanto mais o princípio do que vemos escapa ao ver, mais fortemente se faz sentir a necessidade de uma fenomenologia não intencional e mais se imporá o seu poder.

Assim são muitos os desenvolvimentos que ainda virão contribuir à psicologia clínica, seja ela psicoterapêutica, psicanalítica ou humanista, que possam fundamentar os alicerces de uma renovação necessária no mundo contemporâneo.

Roland Vaschalde (2006, p. 158) afirma que a relação terapêutica se perfaz como um encontro ético, de uma ética que se enraíza na intersubjetividade patética pro- 
vada por dois sujeitos encarnados, numa relação afetiva recíproca, na qual "conhecem” a angústia, o sofrimento, o prazer, a felicidade do outro, não mais pela intermediação de um saber teórico, mas fundamentalmente porque eles próprios se provam a si em tal realidade impressional que é sua essência comum, a esfera de uma realidade originária.

De modo que a alteridade é também um conceito fundamental. De acordo com Henry (2002, p. 8) "a fenomenologia da Vida obriga a repensar toda e qualquer questão essencial, nomeadamente a experiência do outro". Henry reconhece que a obra Recuperar o humanismo (Martins, 2002a) busca "compreender, com acuidade, a essência da revelação própria da Vida” e renova o problema da alteridade ao retirar o foco do "fora de si". Ele afirma: "nunca é do ego que devemos partir; a intersubjetividade não é uma relação entre "ego(s)" (...) "mas do ser-com o outro, de todos os Si(s) - presentes, passados e futuros". Henry (2002, p. 9) reconhece que a obra "mostra de forma exemplar como é que a imanência de Si na Vida abre a dimensão de uma transcendência real que não é a dispersão numa exterioridade vazia e fantasmagórica. O que é antes de nós 'antes do nosso Si, do nosso eu e do nosso ego' dá-se em nós, que n'Ele somos com os outros", de modo que:

avança em uma nova concepção de alteridade, não é um simples desenvolvimento da fenomenologia clássica - ele desenlaça uma outra fenomenologia. Texto fundamental que requer desde já a atenção de todos os que se interessam pelos movimentos actuais da fenomenologia e, através desta, pelo devir da nossa cultura.

Assim, dialogando com a fenomenologia de Michel Henry podemos refletir sobre a clínica e a relação terapêutica, onde estas ocupam um lugar especial e de intimidade que acolhe a experiência afetiva de si, pois revaloriza a dimensão do encontro e a especificidade da relação terapêutica. Assim, há um co-pathos, do terapeuta e do paciente, onde a com-paixão é a capacidade de se autoafetar pelo pathos do outro. Nesse sentido, a melancolia e depressões ou os traumas e impasses psíquicos não constituem uma paragem de uma subjetividade afetiva, mas uma possibilidade para viver, ao sustentar o originário e o irrepresentável, para que possamos ter a esperança que o sofrimento possa se transformar em fruir da Vida.

\section{Referências}

Birman, J. (2007). Escritura e psicanálise: Derrida, leitor de Freud. Natureza Humana, 9 (2), pp. 275-298.

Cardoso, A. (2010). Em R. Kühn, Ipseidade e práxis subjectiva - Abordagens fenomenológicas e antropológicas segundo o pensamento de Michel Henry. Lisboa: Edições Colibri.
Faÿ, E. \& Le Guyader, S. (2009). Michel Henry and Critical Theory, an Introductory Standpoint: The case of virtual organization. 6th International Critical Management Studies Conference, Universidade de Warwick, GB. Disponível em: http://mngt.waikato.ac.nz/ejrot/cmsconference/2009/ Stream10/Henry\%20Critique\%20and\%20VO\%20Faÿ\%20 FV.pdf

Green, A. (1998). Sobre a discriminação e a indiscriminação afeto-representação. Revista Brasileira de Psicanálise, 32 (3), pp. 407-456.

Henry, M. (1954). Le jeune officier. Paris: Gallimard.

Henry, M. (1976). Marx, t.I. Paris: Gallimard.

Henry, M. (2001). Encarnação: por uma filosofia da carne. Lisboa: Circulo de Leitores.

Henry, M. (2002). Prefácio. Em F. Martins, Recuperar o Humanismo - Para uma fenomenologia da alteridade em Michel Henry (pp. 07-09). Cascais, Portugal: Principia, Publicações Universitárias e Científicas.

Henry, M. (2005). Phänomenologie und Psychoanalyse. Em Affekt und Subjektivität, Lebensphänomenologische Beiträge zur Psychologie und zum Wesen des Menschen. Freiburgo, pp. 106-123. Munique, Alber.

Henry, M. (2006). Fenomenologia não-intencional. Phénoménologie non intencionelle: une tàche por une phénoménologie à venir. Phainomenon (Centro de Filosofia da Universidade de Lisboa), Vol. 13, pp. 165-177. Disponível em: http://www.lusosofia.net/textos/michel_henry_fenomenologia_nao_intencional.pdf

Henry, M. (2007). Entretiens. Paris: Sulliver.

Henry, M. (2009). Genealogia da psicanálise - o começo perdido. Curitiba: Editora UFPR.

Husserl, E. (1970). The crisis of European Sciences and transcendental phenomenology. Evanston: Northwestern University Press.

Kühn, R. (2010). Ipseidade e práxis subjectiva - Abordagens fenomenológicas e antropológicas segundo o pensamento de Michel Henry. Lisboa: Edições Colibri.

Kristeva, J. (1988). Histórias de amor. Rio de Janeiro: Paz e Terra.

Lipsitz, M. (2004). Eros y nacimiento fuera de la ontología griega. Emmanuel Levinas y Michel Henry. Buenos Aires: Prometeo.

Lipsitz, M. (2008). Michel Henry y la crítica del Intuicionismo. A Parte Rei. Revista de Filosofía, 10, pp. 1-5.

Magalhães, F. S. R. (2008). Caro cardo salutis: O Contributo de Michel Henry para uma Cristologia da Encarnação. Dissertação de Mestrado, Universidade Católica Portuguesa, Porto.

Martins, F. (2002a). Recuperar o Humanismo - Para uma fenomenologia da alteridade em Michel Henry. Principia, Publicações Universitárias e Científicas: Cascais. 
Martins, F. (2002b). O impossível do sofrimento - indecisões fenomenológicas no romance Le fils du roi. Filosofia (Revista da Faculdade de Letras), v. XIX, II Série. Porto: Universidade do Porto.

Martins, F. (2009). Apresentação a Henry, M. Genealogia da psicanálise: o começo perdido, pp. 9-33. Curitiba: UFPR.

Martins, F \& Teixeira, M. C. (2007). Tecidos de afectos em fios quatro-zero. Lisboa: Edições Colibri.

Martins, F. (2010). O que pode um corpo? Apresentação do Projecto. Em F. Martins \& A. Pereira, Michel Henry: O que pode um corpo? Contributos em língua portuguesa para um projecto internacional de investigação em rede, pp. 11-38. Lisboa: Universidade Católica Editora.

Paincera, A. (2002). Hacia una nueva teorización del psicoanálisis a partir de la "intuición fundamental" de Winnicott. Revista Psicoanálisis ApdeBA, v. XXIV, n. 3, p. 533.

Plastino, C. A. (2001). O primado da afetividade. Rio de Janeiro: Relume-Dumará.

Safra, G. (2004). A po-ética na clínica contemporânea. Aparecida, São Paulo: Idéias e Letras.

Schneider, M. (1993). Afeto e linguagem nos primeiros escritos de Freud. São Paulo: Escuta.

Vaschalde, R. (2006). Maladie: de la phénomenologie a la théraphie. Phainomenon (Centro de Filosofia da Universidade de Lisboa), Vol. 13, p. 158.

Winnicott, D. W. (1975). O brincar e a realidade. Porto Alegre: Editora Imago.

Wondracek, K. H. K. (2008). Cristianismo como Filosofia: uma introdução à Fenomenologia da Vida de Michel Henry. VII Salão de Pesquisa da Faculdades EST, São Leopoldo. Anais do VII Salão de Pesquisa Faculdades EST [CD-Rom].
Wondracek, K. H. K. (2009). Da felicidade ao pathos: uma introdução à fenomenologia da Vida de Michel Henry. Disponível em http://www.sig.org.br/_files/artigos/dafelicidadeaopathosumaintroduofenomenologiadavidademichelhenry.pdf

Wondracek, K. H. K. (2010a). Ser nascido na Vida: a fenomenologia da Vida de Michel Henry e sua contribuição para a clínica. Tese de doutorado. São Leopoldo: Escola Superior de Teologia. Disponível em: http:/tede.est.edu.br/tede/tde busca/arquivo.php?codArquivo $=245$

Wondracek, K. H. K. (2010b). Fenomenologia da Vida no Brasil. Em F. Martins \& A. Pereira, Michel Henry: O que pode um corpo? Contributos em língua portuguesa para um projecto internacional de investigação em rede, pp. 161-166. Lisboa: Universidade Católica Editora.

Andrés Eduardo Aguirre Antúnez - Doutor em Saúde Mental, Professor de Graduação e Pós-Graduação do Departamento de Psicologia Clínica, Instituto de Psicologia da Universidade de São Paulo. Endereço Institucional: Universidade de São Paulo. Av. Prof. Mello Moraes, 1721 (Cidade Universitária). CEP 05508-030 - São Paulo/ SP.E-mail: antunez@usp.br

Karin Hellen Kepler Wondracek - Doutora em Teologia e Psicanalista, Professora de Graduação e Pós-graduação na Faculdades EST, São Leopoldo e docente na Sigmund Freud Associação Psicanalítica de Porto Alegre RS. Endereço Institucional: Rua Amadeo Rossi, 467. 93001-970 São Leopoldo/RS. E-mail: karinkw@gmail.com

Recebido em 20.03.12

Aceito em 12.06.12 